\title{
Surgery-induced iris abnormalities after Descemet membrane endothelial keratoplasty and their impact on postoperative clinical outcomes
}

This article was published in the following Dove Press journal:

Clinical Ophthalmology

\author{
Natsuko Mori ${ }^{1,2}$ \\ Hideaki Yokogawa' \\ Akira Kobayashi' \\ Tsubasa Nishino ${ }^{1,3}$ \\ Kazuhisa Sugiyama' \\ 'Department of Ophthalmology, \\ Kanazawa University Graduate School of \\ Medical Science, Kanazawa, Japan; \\ ${ }^{2}$ Department of Ophthalmology, Saiseikai \\ Kanazawa Hospital, Kanazawa, Japan; \\ ${ }^{3}$ Department of Ophthalmology, Toyama \\ Prefectural Central Hospital, Toyama, \\ Japan
}

\begin{abstract}
Purpose: This study aimed to elucidate the frequency of surgery-induced iris abnormalities after Descemet membrane endothelial keratoplasty (DMEK) and their impact on postopera-
\end{abstract} tive clinical outcomes.

Methods: In this retrospective study, medical records of 32 eyes from 28 consecutive patients (mean age, 65.7 \pm 13.4 years; 14 men, 18 women) who underwent DMEK (or triple DMEK) were reviewed. In all patients, inferior peripheral iridectomy was created leaving full intracameral air tamponade at the end of surgery. Sulfur hexafluoride gas was not used in any cases. Surgery-induced iris abnormalities such as pupillary shape changes and iris depigmentation were evaluated by 3 masked observers. Pre-existing abnormalities were excluded. Eyes were divided into two groups based on the presence of surgery-induced iris changes: Group A (with iris abnormalities) and Group B (without). Impacts on postoperative clinical outcomes such as vision and endothelial cell density were analyzed.

Results: Surgery-induced iris abnormalities were seen in 15 eyes (Group A, 9 with pupillary shape change and 6 with iris depigmentation; 46.9\%), and 17 eyes showed no abnormalities (Group B, 53.1\%). No significant differences were detected between groups in age, sex, indication, simultaneous cataract surgery, pre- and 6-month postoperative vision, donor age, donor endothelial cell density, and 6- and 12-month postoperative endothelial cell density.

Conclusions: Surgery-induced iris abnormalities were noted in almost half of the eyes after DMEK (46.9\%) in this study. However, there was no association between visual outcomes or postoperative endothelial cell density and the iris changes.

Keywords: surgery-induced iris abnormalities, DMEK

\section{Introduction}

Endothelial keratoplasty is a selective transplantation for patients with corneal endothelial diseases such as Fuchs endothelial dystrophy and bullous keratoplasty. Descemet membrane endothelial keratoplasty (DMEK), the latest technique, involves the selective replacement of the diseased host Descemet membrane and endothelium with healthy donor tissue, and provides excellent visual outcomes. ${ }^{1-3}$ Despite the remarkable visual recovery, a major post-DMEK complication is graft detachment, which may require rebubbling. Other unfavorable events, such as intraocular pressure (IOP) elevation, graft failure, immune rejection, cystoid macular edema, and iris abnormalities, have been reported. ${ }^{4-7}$

Surgery-induced iris abnormalities can occur after both types of endothelial keratoplasty, DMEK and Descemet stripping automated endothelial keratoplasty
Correspondence: Hideaki Yokogawa Department of Ophthalmology, Kanazawa University Graduate School of Medical Science, I3-I Takara-machi, Kanazawa-shi, Ishikawa-ken 920864I, Japan

Tel +8 I76 2652403

Fax +8176 2229660

Email hyoko@med.kanazawa-u.ac.jp 
(DSAEK) ${ }^{5-10}$ These surgery-induced iris abnormalities include posterior synechiae, damage, and ischemia. However, clinical manifestation of these iris changes after DMEK have not received adequate attention in past research. The purpose of this study was to elucidate the frequency of surgery-induced iris abnormalities after DMEK and their impact on postoperative clinical outcomes.

\section{Methods}

This retrospective chart review was approved by the Ethical Committee of Kanazawa University Graduate School of Medical Science (approval number 2017-222 (2659)) and adheres to the tenets of the Declaration of Helsinki. Written informed consent was obtained from all patients. Medical records of 32 eyes from 28 consecutive patients (mean age, 65.7 \pm 13.4 years; 14 men, 18 women) who underwent DMEK or triple DMEK (DMEK with phacoemulsification and intraocular lens placement) in our hospital were reviewed (Table 1). All patients undergoing solitary DMEK had pseudophakic eyes.

DMEK or triple DMEK was performed as previously described. ${ }^{3,11}$ In brief, a $2.4 \mathrm{~mm}$ temporal clear corneal incision was made in the host. In patients undergoing triple DMEK, cataract surgery was performed through the same incision. Approximately $9.0 \mathrm{~mm}$ diameter of the host Descemet membrane was removed. An inferior iridectomy was created using a 25-gauge vitreous cutter. All pre-stripped and s-stamped DMEK donor tissues were internationally shipped from an eye bank in the USA (SightLife, Seattle, WA). The donor graft roll ( $8.0 \mathrm{~mm}$ in diameter) was stained with $0.06 \%$ trypan blue (Vision Blue ${ }^{\circledR}, \mathrm{DORC}$, Zuidland, The Netherlands) for four minutes, then was inserted into the anterior chamber using a DMEK shooter (G-38630, Geuder, Heidelberg, Germany).

Table I Demographics of 32 eyes from 28 patients who underwent DMEK (or triple DMEK)

\begin{tabular}{|l|l|}
\hline Total number of eyes & 32 \\
Age (years), mean \pm SD & $65.7 \pm \mid 3.4$ \\
Sex (male: female) & $14: 18$ \\
\hline $\begin{array}{l}\text { Indications of DMEK, number of eyes (\%) } \\
\text { Fuchs endothelial dystrophy }\end{array}$ & $13(40.6 \%)$ \\
Endothelial dysfunction associated with laser & $12(37.5 \%)$ \\
iridotomy & $2(6.3 \%)$ \\
Pseudophakic bullous keratopathy & $5(15.6 \%)$ \\
\hline Others & $25: 7$ \\
\hline Procedure (solitary DMEK: triple DMEK) & \\
\hline
\end{tabular}

Abbreviation: DMEK, Descemet membrane endothelial keratoplasty.
After securing the wound with one 10-0 nylon suture, the graft roll was correctly oriented with the endothelial side facing down. A small air bubble was then injected over the graft and used to unfold the graft. To obtain further visualization, oblique light via an endoillumination probe was used. An assistant surgeon attached the endoillumination probe at the peripheral cornea. The orientation of the DMEK donor tissue was confirmed by intraoperative spectral domain optical coherence tomography using the RESCAN 700 (Carl Zeiss Meditec, Germany). Finally, the anterior chamber was filled with air to completely adhere the graft to the posterior stromal surface; nearly full intracameral air was maintained at the end of surgery. Sulfur hexafluoride $\left(\mathrm{SF}_{6}\right)$ gas was not used in any case. At the end of the surgery, $125 \mathrm{mg}$ of methylprednisolone was injected intravenously, and $1.65 \mathrm{mg}$ of dexamethasone was injected subconjunctivally. The patient was instructed to lie on his or her back for $2-3 \mathrm{hrs}$. Postoperatively, topical $0.5 \%$ levofloxacin was applied 5 times per day and topical $0.1 \%$ betamethasone was also applied 5 times per day. These eye drops continued for 3 months then were tapered. At every postoperative visit, the patient underwent ocular examination and slit-lamp photography.

For evaluation of surgery-induced iris abnormalities, comparisons between pre- and 6-month postoperative slitlamp photographs were performed by 3 independent corneal specialists in a masked fashion. The agreement of two or more observers confirmed the existence of iris abnormalities, including pupillary shape change and iris depigmentation (Figure 1). Inferior peripheral iridectomy during DMEK and pre-existing iris abnormalities were excluded from this evaluation.

Eyes were divided into two groups based on the presence of these surgery-induced iris changes: Group A (with iris abnormalities) and Group B (without iris abnormalities). The impact of surgery-induced iris changes on postoperative clinical outcomes between the two groups was analyzed; this included the 6-month best corrected visual acuity and 6- and 12-month endothelial cell density (ECD).

Statistical analysis was performed using SPSS version 23 (SPSS, Inc., Chicago, IL). Comparisons between the two groups were performed using the Mann-Whitney test, and $P$-values of less than 0.05 were considered statistically significant.

\section{Results}

Surgery-induced iris abnormalities were present in 15 eyes (Group A, 46.9\%), and were absent in 17 eyes (Group B, $53.1 \%$ ). In Group A, ovalization of the pupil (9 eyes) and 

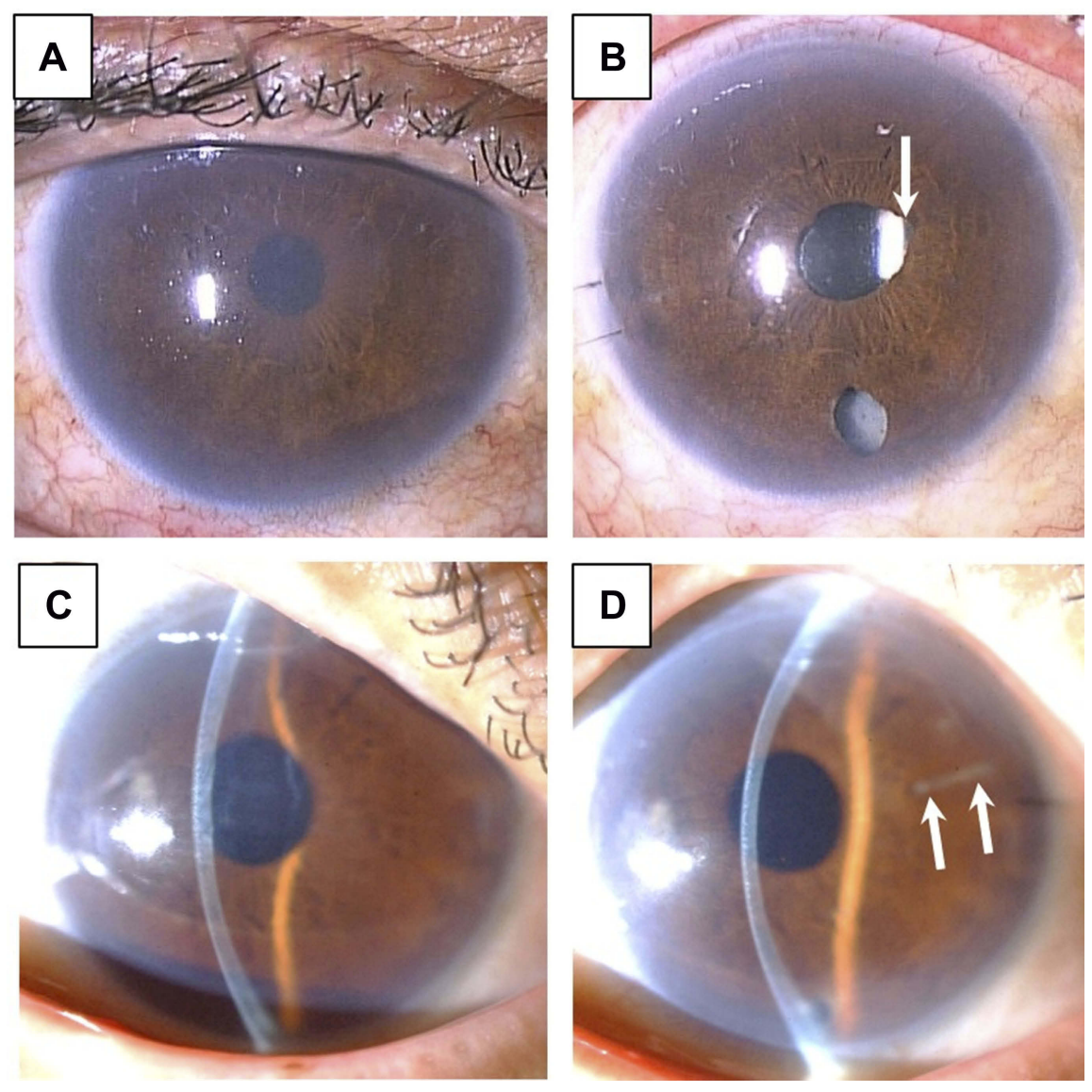

Figure I Representative cases with surgery-induced iris abnormalities after DMEK. (A) Case I: a 69-year-old man had bullous keratopathy after cytomegalovirus corneal endotheliitis in his right eye. This eye was pseudophakic. (B) Case I, after solitary DMEK, mild ovalization of the pupil (arrow), likely due to posterior synechiae, was noted. (C) Case 2: a 73-year-old woman had laser iridotomy-related bullous keratopathy in her right eye. This eye was pseudophakic. (D) Case 2, after solitary DMEK, mild iris depigmentation (arrows) was detected near the temporal wound.

mild iris depigmentation (6 eyes) were noted (Figure 1). There were no severe changes, such as mid-dilated pupil, displaced pupil, or iris atrophy larger than an octant. The location of depigmentation was near the temporal wound ( 5 eyes) and in the nasal quadrant (1 eye). No patients required surgical release of the iris from posterior synechiae. No differences were detected between Group A and Group $\mathrm{B}$ in age $(P=0.60)$, sex $(P=0.31)$, indication $(P=0.13)$, simultaneous cataract surgery $(P=0.40)$, preand 6-month postoperative vision $(P=0.11$ and 0.65$)$, donor age $(P=0.52)$, donor $\operatorname{ECD}(P=0.66)$, and 6- and 12month postoperative $\operatorname{ECD}(P=0.70$ and 0.87$)$ (Table 2$)$.

\section{Discussion}

In the present study we found that DMEK surgery induced iris abnormalities in almost half of the eyes evaluated (15 eyes, 46.9\%). These surgery-induced iris abnormalities included pupillary shape changes (9 eyes, 28.1\%) and iris depigmentation (6 eyes, 18.8\%). Pupillary shape changes indicated iris posterior synechiae formation. Shimizu et al had reported high frequency of posterior synechiae (20 out of 23 eyes $(87.0 \%))$ after DMEK. ${ }^{6}$ They found that short axial length and preexisting iris damage was correlated with iris posterior synechiae. Also, they speculated that postoperative inflammation caused iris posterior synechiae in cases with previous laser iridotomy or pseudoexfoliation syndrome. There are two possible explanation for lower frequency of iris posterior synechiae in our study than in Shimizu's study. First, the inflammation was reduced by routine intraoperative intravenous injection of $125 \mathrm{mg}$ of methylprednisolone in our cases. Second, since we did not use 3-mirror lens or dilatation for evaluation of iris posterior synechiae, we were not able to detect faint synechiae with almost normal pupillary shape. On the other hand, Arnalich-Montiel et al reported nonischemic pupillary abnormalities in 18 out of 32 eyes $(56 \%)$ after nearly full tamponade DMEK. ${ }^{7}$ Among those eyes, 10 (31\%) had relatively severe changes, displaced or middilated pupil resulting from posterior synechiae. ${ }^{7}$ While Arnalich-Montiel et al used intracameral air or long-lasting $20 \% \mathrm{SF}_{6}$ gas, we used only room air in our patients. The use 
Table 2 Comparison between Group A (with surgery-induced iris abnormalities) and Group B (without surgery-induced iris abnormalities)

\begin{tabular}{|c|c|c|c|}
\hline & $\begin{array}{l}\text { Group } A \text { (with surgery-induced } \\
\text { iris abnormalities), } n=I 5\end{array}$ & $\begin{array}{l}\text { Group B (without surgery- } \\
\text { induced iris abnormalities), } n=17\end{array}$ & $P$-value* \\
\hline Patient age (years), mean $\pm S D$ & $68.3 \pm 8.9$ & $66.6 \pm 9.8$ & 0.60 \\
\hline Sex (male: female) & 5: 10 & 9: 8 & 0.31 \\
\hline $\begin{array}{l}\text { Indications of DMEK (Fuchs endothelial dys- } \\
\text { trophy: LIBK: others) }\end{array}$ & 4: 7: 4 & 9: $5: 3$ & 0.13 \\
\hline Procedure (solitary DMEK: triple DMEK) & 13: 2 & 12: 5 & 0.40 \\
\hline Preoperative vision (LogMAR), mean \pm SD & $0.66 \pm 0.46$ & $0.44 \pm 0.41$ & 0.11 \\
\hline $\begin{array}{l}\text { Six-month postoperative vision (LogMAR), } \\
\text { mean } \pm \text { SD }\end{array}$ & $0.21 \pm 0.38$ & $0.07 \pm 0.20$ & 0.65 \\
\hline Donor age (years), mean $\pm S D$ & $59.6 \pm 10.1$ & $61.7 \pm 10.4$ & 0.52 \\
\hline $\begin{array}{l}\left.\text { Preoperative donor ECD (cells } / \mathrm{mm}^{2}\right) \text {, mean } \\
\pm \mathrm{SD}\end{array}$ & $2790 \pm 246$ & $2733 \pm 194$ & 0.66 \\
\hline $\begin{array}{l}\text { Six-month postoperative ECD }\left(\text { cells } / \mathrm{mm}^{2}\right) \\
\text { mean } \pm S D\end{array}$ & $1684 \pm 659$ & $1673 \pm 553$ & 0.70 \\
\hline $\begin{array}{l}\left.\text { One-year postoperative ECD (cells } / \mathrm{mm}^{2}\right) \\
\text { mean } \pm \text { SD }\end{array}$ & $|5| 4 \pm 67 \mid$ & $1434 \pm 576$ & 0.87 \\
\hline
\end{tabular}

Note: *Mann-Whitney $U$ test.

Abbreviations: DMEK, Descemet membrane endothelial keratoplasty; LIBK, laser iridotomy-induced bullous keratopathy; ECD, endothelial cell density.

of $20 \% \mathrm{SF}_{6}$ tamponade instead of air provides better graft adhesion in DMEK. ${ }^{12,13}$ Since intracameral gas pushes the iris backwards, intensive management of the pupil using mydriatics might be necessary to prevent posterior synechiae. Although Arnalich-Montiel et al found that performing a triple procedure (combined DMEK and cataract surgery) was a risk factor for pupillary abnormalities, we could not find any association between pupillary shape change and triple procedures. In our study, all 7 cases that underwent a triple procedure had normal round pupils.

Iris abnormalities have been reported after both DMEK and DSAEK. ${ }^{5-10}$ The use of intracameral gas is a known risk for IOP elevation with or without pupillary block. ${ }^{14}$ IOP elevation during the early postoperative period could induce ischemic pupillary changes, such as variants of Urrets-Zavalia syndrome. $^{5,8}$ The frequency of surgery-induced iris abnormalities might be greater in DMEK $(56-87 \%)^{6,7}$ than in DSAEK (12-37.5\%). ${ }^{9,10}$

In the brown irises of Japanese patients, iris depigmentation can be more evident than in other ethnicities. In the current study, mild iris depigmentation was noted in 6 eyes. The depigmentation mainly occurred around the temporal wound. Because the anterior chamber becomes shallow during the unscrolling of the donor tissue, the iris might touch the temporal wound. In addition, needle entry via the temporal wound could contact the iris. In 2 of the present cases that underwent a triple procedure, the phaco tip could have induced iris damage. It is also possible that the increased manipulation of the eye may increase the risk of iris damage.

This is the first study to investigate the impact of surgery-induced iris changes on clinical outcomes after DMEK. In our patients, the severity of pupillary shape change was mild, and we did not find any correlation between surgery-induced iris abnormalities and postoperative visual acuity. However, pupillary shape could potentially affect visual function, such as contrast sensitivity and higher-order aberrations. In future studies, the measurement of contrast sensitivity and wave front analysis should be considered in order to determine the influence of these pupillary shape changes on vision quality.

We did not find any differences in the ECD outcomes at 6 or 12 months regardless of the presence of iris changes. In a long-term study of DSAEK, rapid reduction of ECD and graft failure were associated with immune rejection and postglaucoma surgery. ${ }^{15,16}$ Recently, Ishii et al reported that severe preexisting iris damage was a significant predisposing factor for ECD loss after DSAEK. ${ }^{10}$ They also found that eyes with severe iris damage were associated with elevated levels of inflammatory cytokines in the aqueous humor, which could cause endothelial cell loss. ${ }^{17}$ Similar to DSAEK, a longer study period using a larger number of patients might be necessary to fully determine the association between iris damage and ECD 
after DMEK. The limitations of this study include the small number of patients and the lack of anterior segment OCT imaging which could preclude full characterization of iris morphology.

In conclusion, surgery-induced iris abnormalities were observed in almost half of our patients after DMEK (46.9\%). There was no association between visual outcomes or postoperative ECD and the iris changes at least 12 months postoperatively. Further comparative long-term studies using a larger number of patients are needed to elucidate the clinical significance of morphological changes to the iris after DMEK.

\section{Disclosure}

The authors report no conflicts of interest in this work.

\section{References}

1. Melles GR, Ong TS, Ververs B, van der Wees J. Descemet membrane endothelial keratoplasty (DMEK). Cornea. 2006;25:987-990. doi:10.1097/01.ico.0000248385.16896.34

2. Hamzaoglu EC, Straiko MD, Mayko ZM, Sáles CS, Terry MA. The first 100 eyes of standardized descemet stripping automated endothelial keratoplasty versus standardized Descemet membrane endothelial keratoplasty at one institution. Ophthalmology. 2015;122:2193-2199. doi:10.1016/j.ophtha.2015.07.003

3. Kobayashi A, Yokogawa H, Yamazaki N, Masaki T, Sugiyama K. In vivo laser confocal microscopy after Descemet's membrane endothelial keratoplasty. Ophthalmology. 2013;120:923-930. doi:10.1016/j. ophtha.2012.11.006

4. Quilendrino R, Rodriguez-Calvo de Mora M, Baydoun L, et al. Prevention and management of Descemet membrane endothelial keratoplasty complications. Cornea. 2017;36:1089-1095. doi:10.1097/ ICO.0000000000001262

5. Holtmann C, Spaniol K, Geerling G. Urrets-Zavalia syndrome after Descemet membrane endothelial keratoplasty. Eur $J$ Ophthalmol. 2015;25:e75-e77. doi:10.5301/ejo.5000597

6. Shimizu T, Hayashi T, Yuda K, et al. Short axial length and iris damage are associated with iris posterior synechiae after Descemet membrane endothelial keratoplasty in Asian eyes. Cornea. 2018;37:1355-1359. doi:10.1097/ICO.0000000000001698
7. Arnalich-Montiel F, Pérez-Sarriegui A, Lauzirika G, Porrua L, Hernández-Verdejo JL. Pupillary abnormalities in Descemet membrane endothelial keratoplasty after nearly full tamponade. Cornea. 2017;36:290-294. doi:10.1097/ICO.0000000000001141

8. Anwar DS, Chu CY, Prasher P, Bowman RW, Mootha VV. Features of Urrets-Zavalia syndrome after Descemet stripping automated endothelial keratoplasty. Cornea. 2012;31:1330-1334. doi:10.1097/ ICO.0b013e318259ca15

9. Del Hierro Zarzuelo A, Boto de Los Bueis A. Iris alterations after DSAEK. Arch Soc Esp Oftalmol. 2016;91:422-425. doi:10.1016/j. oftal.2016.02.005

10. Ishii N, Yamaguchi T, Yazu H, Satake Y, Yoshida A, Shimazaki J. Factors associated with graft survival and endothelial cell density after Descemet's stripping automated endothelial keratoplasty. Sci Rep. 2016;6:25276. doi:10.1038/srep25276

11. Kobayashi A, Yokogawa H, Yamazaki N, Masaki T, Sugiyama K. The use of endoillumination probe-assisted Descemet membrane endothelial keratoplasty for bullous keratopathy secondary to argon laser iridotomy. Clin Ophthalmol. 2015;9:91-93. doi:10.2147/OPTH.S74981

12. Terry MA, Straiko MD, Veldman PB, et al. Standardized DMEK technique: reducing complications using prestripped tissue, novel glass injector, and sulfur hexafluoride (SF6) gas. Cornea. 2015;34:845-852. doi:10.1097/ICO.0000000000000479

13. von Marchtaler PV, Weller JM, Kruse FE, Tourtas T. Air versus sulfur hexafluoride gas tamponade in Descemet membrane endothelial keratoplasty: a fellow eye comparison. Cornea. 2018;37:15-19. doi:10.1097/ICO.0000000000001413

14. Röck D, Bartz-Schmidt KU, Röck T, Yoeruek E. Air bubble-induced high intraocular pressure after Descemet membrane endothelial keratoplasty. Cornea. 2016;35:1035-1039. doi:10.1097/ICO.0000 000000000901

15. Price MO, Fairchild KM, Price DA, Price FW. Descemet's stripping endothelial keratoplasty five-year graft survival and endothelial cell loss. Ophthalmology. 2011;118:725-729. doi:10.1016/j.ophtha.2010.08.012

16. Nahum Y, Mimouni M, Busin M. Risk factors predicting the need for graft exchange after Descemet stripping automated endothelial keratoplasty. Cornea. 2015;34:876-879. doi:10.1097/ICO.0000 000000000455

17. Aketa N, Yamaguchi T, Suzuki T, et al. Iris damage is associated with elevated cytokine levels in aqueous humor. Invest Ophthalmol Vis Sci. 2017;58:BIO42-BIO51. doi:10.1167/iovs.17-21421
Clinical Ophthalmology

\section{Publish your work in this journal}

Clinical Ophthalmology is an international, peer-reviewed journal covering all subspecialties within ophthalmology. Key topics include: Optometry; Visual science; Pharmacology and drug therapy in eye diseases; Basic Sciences; Primary and Secondary eye care; Patient Safety and Quality of Care Improvements. This journal is indexed on PubMed
Dovepress

Central and CAS, and is the official journal of The Society of Clinical Ophthalmology (SCO). The manuscript management system is completely online and includes a very quick and fair peer-review system, which is all easy to use. Visit http://www.dovepress.com/ testimonials.php to read real quotes from published authors. 